\title{
Diagnostic value of post-heparin lipase testing in detecting common genetic variants in the $L P L$ and LIPC genes
}

\author{
Mandy van Hoek $^{1}$, Geesje M Dallinga-Thie ${ }^{1}$, Ewout W Steyerberg ${ }^{2}$ and Eric JG Sijbrands ${ }^{\star}, 1$ \\ ${ }^{1}$ Department of Internal Medicine, Erasmus Medical Center, Rotterdam, The Netherlands; ${ }^{2}$ Department of Public \\ Health, Erasmus Medical Center, Rotterdam, The Netherlands
}

Post-heparin lipoprotein lipase and hepatic lipase activities are used to identify primary disorders of triglyceride and HDL-cholesterol metabolism. Their ability to identify common variants in the lipoprotein lipase (LPL) and hepatic lipase (LIPC) genes is unclear. To investigate the ability of lipase testing to detect common lipase gene variants, we included 183 patients who had undergone post-heparin lipase testing and genotyped the LPL D9N, N291S, Pvull, HindIII, and S447X and the LIPC-514CT, V73M, V133V, and N193S polymorphisms. Allele frequencies were compared with 163 controls. Polymorphisms with different allele frequencies in patients and controls or influencing lipids, were analyzed further. The diagnostic value of post-heparin lipase testing was assessed using logistic regression and receiver operating characteristic curves. We found that lipase activities did not predict the LPL D9N and N291S polymorphisms, but predicted the LPL S447X and LIPC-514CT polymorphisms. Adjusted for covariates, the area under the receiver operating characteristic curves was $0.643,0.478,0.686$, and 0.657 for LPL D9N, N291S S447X and LIPC-514CT, respectively. On the basis of these findings, we conclude that high-LPL and low-HL activities associate with the LPL S447X and LIPC-514CT polymorphisms, but low-LPL activity was not related to LPL polymorphisms. Overall, the discriminative ability of post-heparin lipase tests in identifying carriers of common variants in the LPL and LIPC genes was limited. This indicates that conclusions on the genetic causes of lipase activities outside of the normal range should be drawn with caution.

European Journal of Human Genetics (2009) 17, 1386-1393; doi:10.1038/ejhg.2009.61; published online 15 April 2009

Keywords: lipoprotein lipase; hepatic lipase; post-heparin; ROC; LPL; LIPC

\section{Introduction}

In clinical practice, measurements of post-heparin LPL and HL activities are used to identify the cause of primary hypertriglyceridemia (HTG) and disorders of the HDLcholesterol metabolism. In dyslipidemic patients, these tests may identify abnormalities in the LPL or hepatic lipase (HL) gene expression and protein function.

${ }^{*}$ Correspondence: Dr EJG Sijbrands, Department of Internal Medicine Office D435, Erasmus Medical Center, PO-box 2040, 3000 CA Rotterdam, The Netherlands.

Tel: + 3110703 3283; Fax: + 3110703 3639;

E-mail: e.sijbrands@erasmusmc.nl

Received 7 May 2008; revised 22 January 2009; accepted 13 March 2009; published online 15 April 2009
Hypertriglyceridemia results from increased supply to and impaired removal of triglyceride-rich lipoproteins from circulation. Although HTG is a multifactorial disorder, genetic factors clearly influence the disease phenotype. ${ }^{1}$ Notably, it has been shown that genetic factors strongly influence variation in inter-individual HDLcholesterol levels as well. ${ }^{2}$ LPL plays a pivotal role in the metabolism of triglyceride-rich lipoproteins, ${ }^{3}$ whereas HL has a more prominent role in the metabolism of HDL. ${ }^{4}$ In addition, HL is also involved in the conversion of IDL to LDL and influences the LDL size. ${ }^{5,6}$ In line, decreased postheparin LPL activity was associated with elevated plasma triglyceride levels and lower levels of HDL-cholesterol, ${ }^{7,8}$ whereas decreased post-heparin HL activity was associated 
with slightly increased triglyceride and strongly increased HDL-cholesterol levels. ${ }^{8,9}$

Several common sequence variations in the lipoprotein lipase (LPL) and hepatic lipase (LIPC) genes that affect post-heparin lipase activities, have been identified. ${ }^{10-13}$ Subnormal levels of lipase activities are often interpreted as the result of the presence of common polymorphisms. This effect has also been referred to as 'partial lipase deficiency'. ${ }^{14}$ However, the ability of post-heparin lipase testing to identify common genetic $L P L$ and $L I P C$ variants in a dyslipidemic outpatient lipid clinic population has not been investigated.

In this study, we investigated the diagnostic value of post-heparin lipase testing for the detection of common genetic variants of the $L P L$ and $L I P C$ genes in an outpatient lipid clinic population.

\section{Materials and methods Patients}

In our study, we included a total of 183 Caucasian patients who had undergone post-heparin lipase testing at our outpatient clinic between 1991 and 2003. In 128 patients, the primary reason for post-heparin lipase testing was HTG. The remainder of patients had other reasons for lipase testing, such as low HDL-cholesterol $(n=21)$, high HDL-cholesterol $(n=7)$, combined dyslipidemia $(n=7)$, screening for cardiovascular disease risk factors $(n=5)$, hypercholesterolemia $(n=4)$, or other $(n=11)$. Family members, patients under 18 years of age and carriers of the ApoE2/E2 genotype and patients with homozygous LPL or LIPC deficiencies (defined as homozygous carriers of LPL or HL mutations that results in complete loss of function (*3)) were excluded from the analyses.

Collection of clinical data was performed retrospectively by reviewing the patients' medical records. HTG was defined as a serum triglyceride level above $2.3 \mathrm{mmol} / \mathrm{l}$ (204.7 mg per $100 \mathrm{ml}$ ).

Control allele frequencies of the tested polymorphisms were investigated in a population of 163 blood bank donors from Rotterdam Blood Bank, under the assumption that blood bank donors are generally healthy. No other characteristics of these donors were known.

All patients gave their written informed consent for participation in the study. Our local Medical Ethics Committee approved the protocol.

\section{Post-heparin lipoprotein lipase and hepatic lipase activity}

Lipase activities were determined in fasting plasma as described earlier. ${ }^{15}$ In brief, $20 \mathrm{~min}$ after intravenous injection of $50 \mathrm{IU}$ per kg body weight heparin, blood was obtained from the other arm in heparinized tubes and was transported on wet ice to the laboratory. By centrifugation for $10 \mathrm{~min}, 3000$ r.p.m. at $4^{\circ} \mathrm{C}$, plasma was immediately separated. Plasma was stored at $-80^{\circ} \mathrm{C}$ until further analyses. All activity assays used gum acacia-stabilized $\left[{ }^{3} \mathrm{H}\right]$ trioleylglycerol as a substrate. LPL activity was determined after inhibition of HL by co-incubation with a goat antibody to human HL. Fatty acids were extracted as calcium salts and counted in a liquid scintillation counter. $\mathrm{HL}$ activity was measured in the presence of $1 \mathrm{M} \mathrm{NaCl}$, which totally inhibits LPL activity. Activities are expressed as $U / \mathrm{ml}$. One $U$ is defined as the release of $1 \mathrm{nmol}$ $\mathrm{FFA} / \mathrm{ml} / \mathrm{h}$. In every analysis, three to four samples with known LPL and HL activity were analyzed. These controls are stable throughout a long period. New controls were standardized on the old control values so that standardization remains stable. The inter-assay variability is 1.8 and $3.1 \%$ and the intra-assay variability 5.7 and $4.2 \%$ for postheparin LPL and HL activity measurements, respectively.

\section{Laboratory analyses}

Total cholesterol and triglycerides were measured by enzymatic colorimetric methods (CHOD-PAP and GPOPAP, Boehringer Mannheim, Mannheim, Germany) on a Hitachi 911 analyzer (Boehringer Mannheim). HDLcholesterol was measured using a direct enzymatic HDLcholesterol method, using the PEG-modified enzymes method (Boehringer Mannheim) on a Hitachi 911 analyzer. Laboratory values were collected from the day of lipase testing.

\section{DNA analysis}

Genomic DNA was isolated from blood leucocytes with a salting-out procedure. The LPL D9N (rs1801177), N291S (rs268), PvuII (rs285), HindIII (rs320), and S447X(rs328) polymorphisms and LIPC V73M (rs6078), V133V (rs690) N193S (rs6083) polymorphisms were genotyped with Taqman allelic discrimination. The DNA extracted was diluted to a final concentration of $5-10 \mathrm{ng} / \mu \mathrm{l}$. In the assay $1 \mu \mathrm{l}$ DNA solution, $2.5 \mu \mathrm{l}$ Taqman universal PCR Mix and $0.25 \mu \mathrm{l}$ SNP genotyping assay were used. PCR was performed in 40 cycles under standard conditions provided by ABI. Reactions were performed on the Taqman Prism 7900HT platform.

The LIPC-514CT polymorphism was genotyped by determination of the -250GA polymorphism, because these polymorphisms are in complete linkage disequilibrium. ${ }^{16}$ Primers for PCR amplification were $5^{\prime}$-GAT ACT TTG TTA GGG AAG ACT GCC-3' and 5'-GGA TCA CCT CTC AAT GGG TC-3'. PCR was performed in a $25 \mu \mathrm{l}$ reaction mixture with initial denaturation for $5 \mathrm{~min}$ at $95^{\circ} \mathrm{C}$. This was followed by 31 cycles of amplification for $30 \mathrm{~s}$ at $95^{\circ} \mathrm{C}$ annealing at $55^{\circ} \mathrm{C}$ for $30 \mathrm{~s}$, extension at $72^{\circ} \mathrm{C}$ for $60 \mathrm{~s}$, and extension at $72^{\circ} \mathrm{C}$ with Goldstar Taq polymerase (Eurogentec). After digestion of $15 \mu \mathrm{l}$ of PCR mix with $\mathrm{DraI}\left(2 \mathrm{~h}\right.$ at $\left.37^{\circ} \mathrm{C}\right)$ PCR products were separated by electrophoresis on a $2 \%$ agarose gel. 


\section{Statistical analyses}

Continuous variables are expressed as means \pm SD. Comparisons between groups were performed with independent samples $t$-tests and $\chi^{2}$-tests for normally distributed continuous and categorical variables, respectively. ANOVA was used for comparison of continuous variables between more than two groups. Logarithmic transformation was performed on variables that were not normally distributed (ie triglycerides were approximately normally distributed after transformation $\left({ }^{\star} 2\right)$ ). These variables are expressed as medians and their minimum and maximum values. Triglyceride levels were adjusted for the use of fibrates and statins.

Differences in lipid parameters between genotypes were analyzed in the total population, as well as in HTG patients only. Allele frequencies were estimated by gene counting. Deviations from Hardy-Weinberg equilibrium were tested by means of $\chi^{2}$ testing. For all analyses, statistical significance was considered at $P$-values $<0.05$.

Only polymorphisms that differed significantly in allele frequencies between patients and blood bank donors, or that significantly affected post-heparin activities and/or lipid parameters were included in subsequent analyses.

Linear regression models were constructed to estimate the influence of age, sex, environmental factors (BMI, alcohol consumption, diabetes mellitus, insulin use, smoking, use of statins, fibrates, or $\beta$-blockers) and genetic factors on LPL and HL activities. The percentage explained variance $\left(R^{2}\right)$ was calculated in models with and without LPL and LIPC polymorphisms.

To calculate the risk of the presence or absence of an $L P L$ or LIPC polymorphism associated with a certain range of post-heparin plasma lipase activity, we created a binary logistic regression model. We divided the post-heparin plasma lipase activities into tertiles. As men and women have different ranges of post-heparin lipase activities, the tertiles were calculated separately for men and women. The presence or absence of a polymorphism was the dependent variable. The tertiles were entered as categorical variables, with the lowest tertile as the reference category. In addition, we calculated the overall $P$-value (for trend) by entering the tertiles as continuous variables. Age, BMI, and alcohol use (units per day) for $L P L$ polymorphisms and age, BMI and fibrate treatment for the LIPC polymorphism, were entered as independent variables. This resulted in odds ratios for having a polymorphism in sex-specific tertiles of post-heparin lipase activity, corrected for covariates.

For our primary analysis, receiver operator characteristic (ROC) curves were constructed by entering post-heparin LPL and HL activities as test variables and the presence or absence of a polymorphism as state variable. We did not compare diagnostic tests and therefore restricted our analyses of the ROC curve its area under the curve (AUC) $\left(1^{*}\right)$. An AUC of 0.5 means total absence of discriminative ability, whereas 1.0 indicates perfect discrimination. For post-heparin LPL activities, ROC curves were made for the D9N, N291S, and S447X polymorphisms. In addition, a ROC curve was constructed for these three polymorphisms together. As $9 \mathrm{~N}$ and $291 \mathrm{~S}$ variant alleles are thought to reduce plasma lipase activity, whereas the $447 \mathrm{X}$ allele is known for its gain of function effect, we reverse-coded the S447X genotypes for analyses in the combined ROC curve. If a person carried a $9 \mathrm{~N}, 291 \mathrm{~S}$, or $447 \mathrm{~S}$ allele, this person was scored 1. Absence of all of these alleles was scored 0 . In the LIPC gene, only the $-514 \mathrm{CT}$ promoter polymorphism was used for ROC curve construction. AUCs were calculated for LPL and HL activities without adjustment for covariates. Subsequently, factors that significantly influenced variation in post-heparin lipase activities in the linear regression models (age, sex, alcohol intake, and the use of fibrates) were included in the model to calculate standardized residuals. Standardized residuals from a linear regression model, with covariates that significantly affect post-heparin lipase activities, reflect the remaining deviation of each person from the regression line. These residuals can therefore be considered to reflect the remaining variation in LPL and HL activities after correction for covariates. To calculate AUCs, we constructed ROC curves adjusted for these covariates by inserting the standardized residuals of each linear regression model as test variable and the presence or absence of a polymorphism as a state variable. ${ }^{17}$

SPSS 12.01 software was used for all statistical analyses.

\section{Results \\ General characteristics}

General characteristics of the patients are shown in Table 1. Of all the patients, $31.1 \%$ had a personal history of cardiovascular disease, $47.5 \%$ had a family history of cardiovascular disease, and $48.6 \%$ were known to have a family history of dyslipidemia. Ten patients (5.5\%) had a history of pancreatitis. Diabetes was present in $10.4 \%$ of patients. On the day of post-heparin lipase testing, $26.2 \%$ of patients were using statins, fibrates, or both.

\section{Allele frequencies}

All allele frequencies were in Hardy-Weinberg equilibrium. The LPL $291 S$ allele was significantly more frequent in patients than in blood bank donors $(P=0.007$, Table 2$)$. In the patient group, we observed significantly less carriers of the $L P L 447 X$ allele $(P=0.003)$. There were no significant differences in allele frequencies of the other polymorphisms between patients and blood bank donors.

\section{Laboratory values}

Table 3 shows plasma lipids and LPL and HL activities according to genotype in the total patient population. 
Table 1 General characteristics of 183 patients of the lipid clinic

\begin{tabular}{lc}
\hline Variables & $\begin{array}{c}\text { Lipid clinic patients } \\
(\mathrm{n}=183)\end{array}$ \\
\hline Age (years) & $46.1 \pm 10.7$ \\
Sex (M/F) (\%) & $72 / 28$ \\
BMI (kg/m $)^{2}$ & $27.4 \pm 5.2$ \\
Presence of diabetes mellitus (\%) & 10.4 \\
Personal history of CVD (\%) & 31.1 \\
Family history of CVD (\%) & 47.5 \\
Family history of dyslipidemia (\%) & 48.6 \\
& \\
Use of statin or fibrate therapy (\%) & 26.2 \\
Statin use (\%) & 16.2 \\
Fibrate use (\%) & 6.1 \\
Statin and fibrate use (\%) & 3.9 \\
Use of $\beta$-blocking agents (\%) & 26.8 \\
Smoking (\%) & 35.5 \\
Total cholesterol (mmol/l) & $6.98 \pm 3.1$ \\
Triglycerides (mmol/l) & $7.87(0.44-63.0)$ \\
HDL-cholesterol (mmol/l) & $0.98 \pm 0.6$ \\
LDL-cholesterol (mmol/l) & $3.32 \pm 1.6$ \\
Post-heparin lipoprotein lipase & $119 \pm 68$ \\
activity (U/ml) & \\
Post-heparin hepatic lipase activity (U/ml) & $428 \pm 177$ \\
\hline
\end{tabular}

Data are expressed as means $\pm S D$. Triglycerides are expressed as median, minimum-maximum between brackets.

Table 2 Minor allele frequencies compared between lipid clinic patients and controls $(* 4)$

\begin{tabular}{llccl}
\hline Gene & Polymorphism & $\begin{array}{c}\text { \% Patients } \\
\text { ( } n \text { carriers) }\end{array}$ & $\begin{array}{l}\text { \% Controls } \\
\text { (n carriers) }\end{array}$ & P-value \\
\hline \multirow{2}{*}{ LPL } & D9N & $2.7(10)$ & $1.8(7)$ & 0.41 \\
& N291S & $7.6(28)$ & $3.0(10)$ & 0.007 \\
& Pvull & $44.8(129)$ & $50.3(128)$ & 0.15 \\
& HindIII & $19.3(61)$ & $24.4(76)$ & 0.1 \\
& S447X & $4.6(17)$ & $10.4(36)$ & 0.003 \\
\multirow{4}{*}{ LIPC } & -514CT & $21.7(72)$ & $22.4(64)$ & 0.84 \\
& V73M & $2.2(8)$ & $4.6(14)$ & 0.08 \\
& V133V & $39.4(118)$ & $43.1(119)$ & 0.33 \\
& N193S & $36.7(114)$ & $35.5(101)$ & 0.76 \\
\hline
\end{tabular}

Carriers of the $L P L 9 \mathrm{~N}$ allele had significantly higher plasma triglyceride levels than non-carriers. Plasma HDLcholesterol levels were not different between the genotype groups. The mean LPL activity was lower in $9 \mathrm{~N}$ carriers, but this did not reach statistical significance. The 291S allele did not show a significant association with plasma HDLcholesterol, triglycerides, or plasma post-heparin LPL activity in the total population. The carriers of the $447 \mathrm{X}$ allele had significantly lower plasma triglyceride levels and higher plasma HDL-cholesterol levels, than non-carriers. In addition, 447X carriers had significantly higher plasma LPL activities. In the LIPC gene, only the $-514 \mathrm{~T}$ allele showed a significant association with plasma HL activity.
The highest plasma HL activities were found in carriers of the $-514 \mathrm{~T}$ allele. There were no differences in plasma lipids between carriers and non-carriers of this allele. None of the other genotyped polymorphisms in the LPL and LIPC genes showed a significant association with lipid levels and lipase activities (Supplementary information 1).

We also performed analyses restricted to the 128 patients with HTG (Supplementary information 2). The association with triglyceride levels originally observed in carriers of the LPL 9N allele in the whole population was borderline significant $(P=0.07)$. The $291 \mathrm{~S}$ allele was associated with significantly lower plasma HDL levels (0.85 vs $0.67 \mathrm{mmol} / \mathrm{l}$; $P=0.01)$ in patients with HTG.

Seven out of the 17 LPL 447X carriers had HTG. Despite normal to high-plasma LPL activities, these carriers had severe dyslipidemia with mean triglyceride levels of $9.5 \pm 3 \mathrm{mmol} / \mathrm{l}$. Although none of the differences between HTG and normotriglyceridemic (NTG) carriers of the $447 \mathrm{X}$ allele were statistically significant, the HTG patients tended to be more overweight (26.3 vs $\left.24.9 \mathrm{~kg} / \mathrm{m}^{2}\right)$, more often to be smokers (4/7 HTG patients vs $1 / 10$ NTG patients), more often suffering from type 2 diabetes (2/7 HTG patients vs 0/10 NTG patients). (Supplementary information 3).

\section{Linear regression models}

Linear regression models showed that post-heparin LPL activity was significantly influenced by age and alcohol consumption. The percentage of explained variance was $17.1 \%$ in the model without genetic factors, which increased to $24 \%$ after adding the D9N, N291S, and S447X polymorphisms. Post-heparin HL activity was significantly influenced by sex and fibrate treatment. The explained variance was $25.5 \%$ before, and $30.8 \%$ after adding the $-514 \mathrm{CT}$ polymorphism to the model.

\section{Logistic regression models}

Table 4 shows the odds ratios for the presence of a polymorphism associated with the different LPL and HL activity tertiles. The D9N and N291S polymorphisms could not be predicted based on LPL tertiles. After adjustment for covariates, the upper tertile showed a significant odds ratio compared with the lowest tertile for the $447 \mathrm{X}$ allele (adjusted $P$-value for trend: 0.03, without adjustment $P$-value for trend: 0.1$)$. The HL activity tertiles significantly predicted the presence of the LIPC-514T allele ( $P$-value for trend; 0.002).

Except for the $S 447 X$ polymorphism, all results were similar with and without adjustment for covariates.

\section{ROC curves}

Figure 1 shows uncorrected and corrected ROC curves. In the corrected ROC curves age, sex, BMI, and alcohol consumption were included for LPL activity, and age, sex, BMI, and fibrate treatment were included for HL activity. 
Table 3 Lipid profile and lipase activities compared between genotypes in all lipid clinic patients

\begin{tabular}{|c|c|c|c|c|c|c|c|}
\hline Gene & Polymorphism & Genotype (n) & Total cholesterol & Triglycerides $^{\mathrm{a}}$ & HDL-cholesterol & Lipoprotein lipase activity & Hepatic lipase activity \\
\hline$L P L$ & D9N & $\begin{array}{l}\text { GG (173) } \\
\text { GA (10) }\end{array}$ & $\begin{array}{c}6.95 \pm 3.2 \\
7.6 \pm 1.8 \\
P=0.53\end{array}$ & $\begin{array}{c}8.0 \pm 9.5 \\
14.5 \pm 7.1 \\
P=0.004\end{array}$ & $\begin{array}{c}0.99 \pm 0.63 \\
0.77 \pm 0.28 \\
P=0.31\end{array}$ & $\begin{array}{c}120 \pm 69 \\
100 \pm 46 \\
P=0.36\end{array}$ & \\
\hline & N291S & $\begin{array}{l}\text { AA (155) } \\
\text { AG (28) }\end{array}$ & $\begin{array}{c}6.96 \pm 3.1 \\
7.2 \pm 3.5 \\
P=0.73\end{array}$ & $\begin{array}{c}8.0 \pm 9.1 \\
10.1 \pm 11.7 \\
P=0.19\end{array}$ & $\begin{array}{c}1.02 \pm 0.62 \\
0.79 \pm 0.42 \\
P=0.08\end{array}$ & $\begin{array}{c}117 \pm 63 \\
129 \pm 91 \\
P=0.39\end{array}$ & \\
\hline & S447X & $\begin{array}{l}\text { CC (166) } \\
\text { CG (17) }\end{array}$ & $\begin{array}{l}7.0 \pm 3.2 \\
6.5 \pm 2.8 \\
P=0.49\end{array}$ & $\begin{array}{l}8.8 \pm 9.7 \\
4.6 \pm 6.4 \\
P=0.004\end{array}$ & $\begin{array}{c}0.95 \pm 0.54 \\
1.3 \pm 0.93 \\
P=0.02\end{array}$ & $\begin{array}{c}115 \pm 63 \\
156 \pm 100 \\
P=0.02\end{array}$ & \\
\hline LIPC & $-514 C \mathrm{CT}$ & $\begin{array}{l}\text { GG (111) } \\
\text { GT (64) } \\
\text { TT (8) }\end{array}$ & $\begin{array}{l}6.9 \pm 3.0 \\
6.7 \pm 2.6 \\
9.5 \pm 6.1 \\
P=0.06\end{array}$ & $\begin{array}{c}7.6 \pm 9.1 \\
8.6 \pm 8.2 \\
16.9 \pm 18.6 \\
P=0.19\end{array}$ & $\begin{array}{c}0.98 \pm 0.55 \\
0.98 \pm 0.68 \\
1.01 \pm 0.67 \\
P=1.0\end{array}$ & & $\begin{array}{l}461 \pm 168 \\
384 \pm 186 \\
328 \pm 151 \\
P=0.005\end{array}$ \\
\hline
\end{tabular}

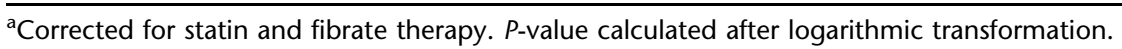

Table 4 Odds ratios for the presence of an LPL or LIPC polymorphism according to lipase activity tertiles

\begin{tabular}{|c|c|c|c|c|c|c|}
\hline \multirow[b]{2}{*}{ Gene } & \multirow[b]{2}{*}{ Polymorphism } & \multicolumn{2}{|c|}{ Tertile } & \multirow[b]{2}{*}{ Odds ratio } & \multirow[b]{2}{*}{$95 \% \mathrm{Cl}$} & \multirow[b]{2}{*}{ P-values for trend } \\
\hline & & Men & Women & & & \\
\hline \multirow[t]{2}{*}{$L P L$} & Combined: D9N, N291S. & $\begin{array}{c}0-86 \\
87-134\end{array}$ & $\begin{array}{c}0-84 \\
85-118\end{array}$ & $\begin{array}{l}1.0 \\
0.69\end{array}$ & $\begin{array}{c}\text { Reference } \\
0.26-1.81\end{array}$ & \\
\hline & & 134-Highest & 119-Highest & 0.76 & $0.30-1.94$ & 0.54 \\
\hline \multirow[t]{2}{*}{$L P L$} & S447X & $\begin{array}{c}0-86 \\
87-134\end{array}$ & $\begin{array}{c}0-84 \\
85-118\end{array}$ & $\begin{array}{l}1.0 \\
4.5\end{array}$ & $\begin{array}{c}\text { Reference } \\
0.84-24.7\end{array}$ & \\
\hline & & 134-Highest & 119-Highest & 6.4 & $1.19-34.9$ & 0.03 \\
\hline \multirow[t]{2}{*}{ LIPC } & $-514 \mathrm{CT}$ & $\begin{array}{c}0-395 \\
396-544\end{array}$ & $\begin{array}{c}0-253 \\
254-359\end{array}$ & $\begin{array}{l}1.0 \\
0.60\end{array}$ & $\begin{array}{c}\text { Reference } \\
0.29-1.25\end{array}$ & \\
\hline & & 545-Highest & 360-Highest & 0.27 & $0.12-0.61$ & 0.002 \\
\hline
\end{tabular}

$\mathrm{LPL}$ corrected for age, $\mathrm{BMI}$ and alcohol consumption; LIPC corrected for age, $\mathrm{BMI}$ and fibrate treatment.

D9N

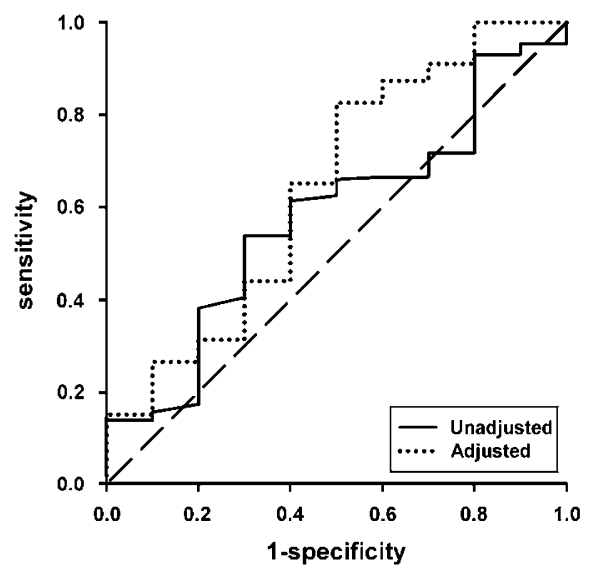

S447X

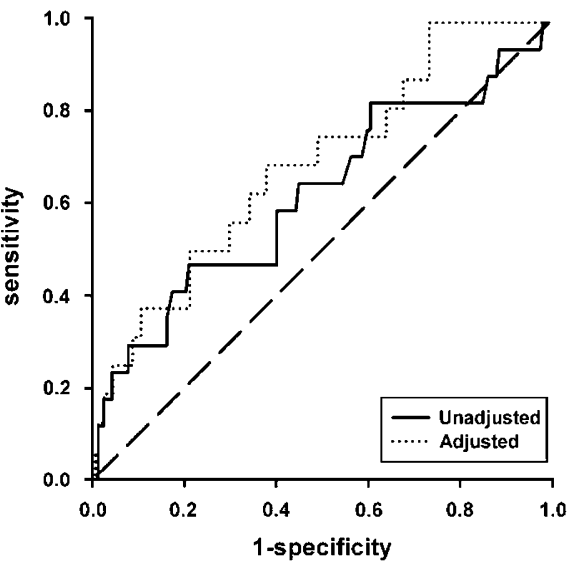

$-514 C T$

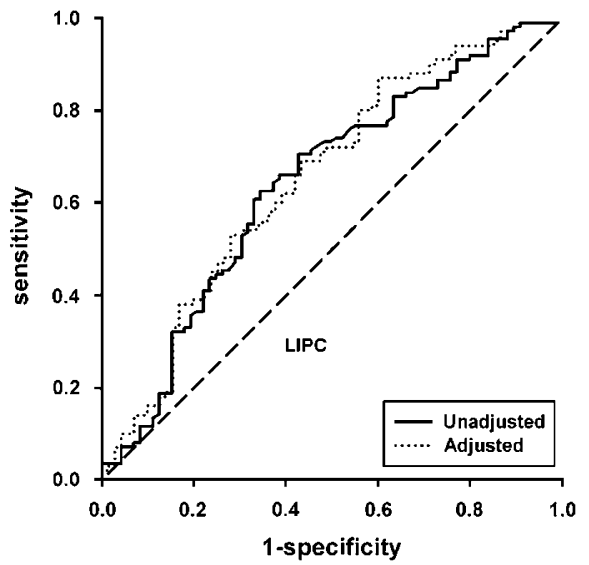

Figure 1 ROC curves for the LPL D9N, S447X, and LIPC-514CT polymorphisms adjusted and unadjusted for covariates.

The ROC curve for the D9N polymorphism had an unadjusted AUC of 0.58 and adjusted AUC of 0.64. For the N291S polymorphism the unadjusted AUC was 0.46 and adjusted AUC was 0.48. (Figures not shown) The uncorrected ROC curve for the LPL S447X polymorphism had an AUC of 0.62, which increased to 0.69 after 
adjustment for covariates. Combination of these three LPL polymorphisms resulted in adjusted and unadjusted curves identical to the curves for the S447X polymorphism alone.

The ROC curves constructed for the LIPC-514CT polymorphism showed an unadjusted AUC of 0.65 that increased to 0.66 after adjustment for covariates.

\section{Discussion}

In this study, we found that post-heparin LPL and HL activity measurements associate with the presence of the LPL S447X and LIPC-514CT polymorphisms. LPL activity lowering polymorphisms (D9N, N291S) did not show significant associations with LPL activity tertiles. Nonetheless, ROC curve analyses showed low AUCs, for all polymorphisms, indicating that the test has limited diagnostic value for the identification of carriers and non-carriers in clinical practice.

Post-heparin plasma LPL and HL activity measurements are performed when a genetic cause of HTG or low HDLcholesterol is suspected, to anticipate the response to treatment. Familial LPL and LIPC deficiency are rare disorders that are caused by homozygosity or compound heterozygosity for mutations that result in complete loss of function. ${ }^{18,19}$ We have excluded these patients from the present analyses. More subtle changes in post-heparin plasma lipase activities are expected in carriers of common, less detrimental, genetic variation that leads to less severe dyslipidemic phenotypes. In clinical practice, subnormal levels of post-heparin lipase activities are often referred to as partial lipase deficiencies. ${ }^{14}$

The patients in our study were recruited from our tertiary outpatient clinic and selected towards severe dyslipidemia. The nature of the dyslipidemic phenotypes in our population was heterogeneous, which introduced large variance of post-heparin lipase values, as is usually is observed when using these tests in clinical practice. By genotyping the nine common genetic variants in the LPL and LIPC lipase genes, we tested the majority of known functional variants in these genes. To our knowledge, this is the first study to investigate the discriminative ability of post-heparin lipase testing in the detection of genetic variants in the $L P L$ and LIPC genes in clinical practice.

Our study population was unfortunately too small to study gene-environment interactions, which have been described for a number of the selected polymorphisms. ${ }^{20-23}$ For instance, the effects of the D9N and N291S polymorphisms become more apparent when the lipolytic system is challenged by environmental factors, such as high BMI and insulin resistance. However, the small effect sizes of the interactions described so far may not substantially influence diagnostic accuracy. Nonetheless, diagnostic value might improve when taking these interactions into account. Another possible limitation of our study is the number of polymorphisms studied. We have genotyped nine polymorphisms, four in the $L I P C$ gene and five in the $L P L$ gene. Especially the $L P L$ gene is highly polymorphic. ${ }^{24}$ Haplotype analyses would require are large number of tag SNP's and a larger study population. Large populations with post-heparin lipase measurements are scarce. We cannot exclude that other, to date unknown, variants in these genes exert significant effects on LPL and HL function. We analyzed the currently known potentially functional genetic variants.

As expected, in our study the $9 \mathrm{~N}$ and $291 \mathrm{~S}$ alleles were more frequent, whereas the $447 \mathrm{X}$ allele was significantly less frequent in dyslipidemic patients than in control subjects. Remarkably, the $447 \mathrm{X}$ allele was present in seven patients with severe HTG. This clearly indicates that other factors, can overrule its beneficial effects. However, overall, our findings are largely in agreement with meta-analyses on the effects of these polymorphisms on plasma lipids and post-heparin lipase activities. ${ }^{11-13,23}$

Logistic regression models of lipase activity tertiles showed significant odds for predicting the presence of the LPL S447X and LIPC-514CT polymorphisms, whereas the tertiles did not significantly associate with LPL activity lowering polymorphisms. Despite these findings, the discriminative ability of the LPL and HL activity measurements, assessed by ROC curve analyses, was low for all polymorphisms. In a study on the effects of the N291S polymorphism in normolipidemic subjects, Mero et al ${ }^{25}$ drew a similar conclusion, being unable to distinguish carrier status by post-heparin LPL activity measurements, because of the wide range of activities in both carriers and non-carriers of this polymorphism.

There are a number of possible explanations for our findings. First, post-heparin plasma lipase testing may not accurately reflect in vivo LPL and HL function. Post-heparin lipase activity measurement is based on the concept that heparin released the active lipase proteins from their proteoglycan-bound sites at the endothelium, reflecting the total putative in vivo catalytic activity at a certain time point. However, it does not reflect the actual availability required under general and pathophysiological circumstances. ${ }^{26}$ Furthermore, non-catalytic ligand and bridging functions of LPL and HL are not reflected by post-heparin lipase activity measurements. ${ }^{27,28}$ If polymorphisms affect non-catalytic functions of the enzymes, we will not observe this by measuring post-heparin lipase activities. Second, lipase activities can be affected by other factors, such as age, sex, BMI, smoking, alcohol consumption, insulin resistance, use of medication, ${ }^{8,29-32}$ and proteins such as ApoCII, ApoCIII, AngPtl3, and LMF1. ${ }^{33-36}$ We adjusted for covariates that had a significant effect on postheparin lipase activities. BMI was included as a covariate, because it is frequently described as a factor influencing post-heparin plasma lipase activities. Correction for covariates resulted in an increase in AUCs, thereby increasing the diagnostic accuracy of the test. AUCs, nonetheless, 
remained below 0.7. Third, there might be other, to date unknown, gene variants affecting LPL and HL activity. Adding these molecular variants to the analyses and performing haplotype analyses might further improve the diagnostic value. However, whether adding additional covariates and genetic variants to the models will substantially improve the diagnostic value is difficult to predict.

In conclusion, we have shown that, although certain polymorphisms associate with post-heparin lipase activities, the tests are unable to accurately identify carriers of well-known common variants in the LPL and LIPC genes in a dyslipidemic population. This indicates that conclusions on the genetic causes of lipase activities outside of the normal range should be drawn with caution.

\section{Disclosure}

The authors have nothing to disclose.

\section{References}

1 Sane T, Nikkila EA: Very low density lipoprotein triglyceride metabolism in relatives of hypertriglyceridemic probands. Evidence for genetic control of triglyceride removal. Arteriosclerosis 1988; 8: 217-226.

2 Perusse L, Rice T, Despres JP et al: Familial resemblance of plasma lipids, lipoproteins and postheparin lipoprotein and hepatic lipases in the HERITAGE Family Study. Arterioscler Thromb Vasc Biol 1997; 17: 3263-3269.

3 Goldberg IJ, Merkel M: Lipoprotein lipase: physiology, biochemistry, and molecular biology. Front Biosci 2001; 6: D388-D405.

4 Cohen JC, Vega GL, Grundy SM: Hepatic lipase: new insights from genetic and metabolic studies. Curr Opin Lipidol 1999; 10: 259-267.

5 Jansen H, van TA, Hulsmann WC: On the metabolic function of heparin-releasable liver lipase. Biochem Biophys Res Commun 1980; 92: $53-59$

6 Zambon A, Austin MA, Brown BG, Hokanson JE, Brunzell JD: Effect of hepatic lipase on LDL in normal men and those with coronary artery disease. Arterioscler Thromb 1993; 13: 147-153.

7 Tornvall P, Olivecrona G, Karpe F, Hamsten A, Olivecrona T: Lipoprotein lipase mass and activity in plasma and their increase after heparin are separate parameters with different relations to plasma lipoproteins. Arterioscler Thromb Vasc Biol 1995; 15: $1086-1093$.

8 Huttunen JK, Ehnholm C, Kekki M, Nikkila EA: Post-heparin plasma lipoprotein lipase and hepatic lipase in normal subjects and in patients with hypertriglyceridaemia: correlations to sex, age and various parameters of triglyceride metabolism. Clin Sci Mol Med 1976; 50: 249-260.

9 Applebaum-Bowden D, Haffner SM, Wahl PW et al: Postheparin plasma triglyceride lipases. Relationships with very low density lipoprotein triglyceride and high density lipoprotein 2 cholesterol. Arteriosclerosis 1985; 5: 273-282.

10 Isaacs A, Sayed-Tabatabaei FA, Njajou OT, Witteman JC, van Duijn CM: The $-514 \mathrm{C} \rightarrow \mathrm{T}$ hepatic lipase promoter region polymorphism and plasma lipids: a meta-analysis. J Clin Endocrinol Metab 2004; 89: 3858-3863.

11 Fisher RM, Humphries SE, Talmud PJ: Common variation in the lipoprotein lipase gene: effects on plasma lipids and risk of atherosclerosis. Atherosclerosis 1997; 135: 145-159.

12 Rip J, Nierman MC, Ross CJ et al: Lipoprotein lipase S447X: a naturally occurring gain-of-function mutation. Arterioscler Thromb Vasc Biol 2006; 26: 1236-1245.
13 Wittrup HH, Tybjaerg-Hansen A, Nordestgaard BG: Lipoprotein lipase mutations, plasma lipids and lipoproteins, and risk of ischemic heart disease. A meta-analysis. Circulation 1999; 99: 2901-2907.

14 Pimstone SN, Gagne SE, Gagne C et al: Mutations in the gene for lipoprotein lipase. A cause for low HDL cholesterol levels in individuals heterozygous for familial hypercholesterolemia. Arterioscler Thromb Vasc Biol 1995; 15: 1704-1712.

15 Jansen H, Hop W, van TA, Bruschke AV, Birkenhager JC: Hepatic lipase and lipoprotein lipase are not major determinants of the low density lipoprotein subclass pattern in human subjects with coronary heart disease. Atherosclerosis 1994; 107: 45-54.

16 Perret B, Mabile L, Martinez L, Terce F, Barbaras R, Collet X: Hepatic lipase: structure/function relationship, synthesis, and regulation. J Lipid Res 2002; 43: 1163-1169.

17 Margaret Sullivan Pepe: The Statistical Evaluation of Medical Tests for Classification and Prediction. Oxford: Oxford University Press, 2003.

18 Connelly PW, Hegele RA: Hepatic lipase deficiency. Crit Rev Clin Lab Sci 1998; 35: 547-572.

19 Mailly F, Palmen J, Muller DP et al: Familial lipoprotein lipase (LPL) deficiency: a catalogue of LPL gene mutations identified in 20 patients from the UK, Sweden, and Italy. Hum Mutat 1997; 10: $465-473$.

20 Fisher RM, Mailly F, Peacock RE et al: Interaction of the lipoprotein lipase asparagine $291->$ serine mutation with body mass index determines elevated plasma triacylglycerol concentrations: a study in hyperlipidemic subjects, myocardial infarction survivors, and healthy adults. J Lipid Res 1995; 36: $2104-2112$.

21 Carr MC, Hokanson JE, Deeb SS, Purnell JQ, Mitchell ES, Brunzell JD: A hepatic lipase gene promoter polymorphism attenuates the increase in hepatic lipase activity with increasing intraabdominal fat in women. Arterioscler Thromb Vasc Biol 1999; 19: 2701-2707.

22 Mailly F, Fisher RM, Nicaud V et al: Association between the LPL-D9N mutation in the lipoprotein lipase gene and plasma lipid traits in myocardial infarction survivors from the ECTIM Study. Atherosclerosis 1996; 122: 21-28.

$23 \mathrm{Hu} \mathrm{Y,} \mathrm{Liu} \mathrm{W,} \mathrm{Huang} \mathrm{R,} \mathrm{Zhang} \mathrm{X:} \mathrm{A} \mathrm{systematic} \mathrm{review} \mathrm{and} \mathrm{meta-}$ analysis of the relationship between lipoprotein lipase Asn291Ser variant and diseases. J Lipid Res 2006; 47: 1908-1914.

24 Nickerson DA, Taylor SL, Weiss KM et al: DNA sequence diversity in a $9.7-\mathrm{kb}$ region of the human lipoprotein lipase gene. Nat Genet 1998; 19: 233-240.

25 Mero N, Suurinkeroinen L, Syvanne M, Knudsen P, Yki-Jarvinen $\mathrm{H}$, Taskinen MR: Delayed clearance of postprandial large TG-rich particles in normolipidemic carriers of LPL Asn291Ser gene variant. J Lipid Res 1999; 40: 1663-1670.

26 Pruneta V, Autran D, Ponsin G et al: Ex vivo measurement of lipoprotein lipase-dependent very low density lipoprotein (VLDL)-triglyceride hydrolysis in human VLDL: an alternative to the postheparin assay of lipoprotein lipase activity? J Clin Endocrinol Metab 2001; 86: 797-803.

27 Heeren J, Niemeier A, Merkel M, Beisiegel U: Endothelial-derived lipoprotein lipase is bound to postprandial triglyceride-rich lipoproteins and mediates their hepatic clearance in vivo. $J \mathrm{Mol}$ Med 2002; 80: 576-584.

28 Merkel M, Heeren J, Dudeck W et al: Inactive lipoprotein lipase (LPL) alone increases selective cholesterol ester uptake in vivo, whereas in the presence of active LPL it also increases triglyceride hydrolysis and whole particle lipoprotein uptake. J Biol Chem 2002; 277: 7405-7411.

29 Berk-Planken II, Hoogerbrugge N, Stolk RP, Bootsma AH, Jansen $\mathrm{H}$ : Atorvastatin dose-dependently decreases hepatic lipase activity in type 2 diabetes: effect of sex and the LIPC promoter variant. Diabetes Care 2003; 26: 427-432.

30 Nie L, Wang J, Clark LT et al: Body mass index and hepatic lipase gene (LIPC) polymorphism jointly influence postheparin plasma hepatic lipase activity. J Lipid Res 1998; 39: 1127-1130. 
31 Staels B, Dallongeville J, Auwerx J, Schoonjans K, Leitersdorf E, Fruchart JC: Mechanism of action of fibrates on lipid and lipoprotein metabolism. Circulation 1998; 98: 2088-2093.

32 Breier C, Lisch HJ, Drexel H, Braunsteiner H: Post-heparin lipolytic activities and alterations of the chemical composition of high density lipoproteins in alcohol-induced type $\mathrm{V}$ hyperlipidemia. Atherosclerosis 1984; 52: 317-327.

33 Fredenrich A: Role of apolipoprotein CIII in triglyceride-rich lipoprotein metabolism. Diabetes Metab 1998; 24: 490-495.
34 McLean LR, Demel RA, Socorro L, Shinomiya M, Jackson RL: Mechanism of action of lipoprotein lipase. Methods Enzymol 1986; 129: $738-763$.

35 Peterfy M, Ben-Zeev O, Mao HZ et al: Mutations in LMF1 cause combined lipase deficiency and severe hypertriglyceridemia. Nat Genet 2007; 39: 1483-1487.

36 Shimizugawa T, Ono M, Shimamura M et al: ANGPTL3 decreases very low density lipoprotein triglyceride clearance by inhibition of lipoprotein lipase. J Biol Chem 2002; 277: 33742-33748.

Supplementary information accompanies the paper on European Journal of Human Genetics website (http://www.nature.com/ejhg) 